International Journal of English Literature and Social Sciences
Vol-6, Issue-5; Sep-Oct, 2021

Peer-Reviewed Journal

\title{
Understanding Gender Roles: Masculine and Feminine
}

\author{
Vishakha Deshwal ${ }^{1, *}$, Dr. A.S. Rao ${ }^{2}$ \\ ${ }^{1} \mathrm{Ph} . \mathrm{D}$. Scholar, English Dept, Mody University, Lakshmangarh, Rajasthan, India \\ ${ }^{2} \mathrm{HOD}$, (English Dept), Mody University, Lakshmangarh, Rajasthan, India \\ *Corresponding Author
}

Received: 13 Aug 2021; Received in revised form: 11 Sep 2021; Accepted: 20 Sep 2021; Available online: 27 Sep 2021

(C)2021 The Author(s). Published by Infogain Publication. This is an open access article under the CC BY license

(https://creativecommons.org/licenses/by/4.0/).

\begin{abstract}
The present study aims to bring out the gender roles through the work of Judith Butler's
"Gender Trouble: Feminism and the Subversion of Identity." How "Gender" is defined and what it signifies. The objective of the study is to bring forth the gender coding, decoding, and recoding. To understand the masculine and feminine aspect of gender along with performativity and embodiment. Therefore, it is an attempt to understand the hype behind "Gender." Hence through systematic study, it aims to raise the question of importance of a gender where women as a "Gender is negligible" and yet plays a significant role in understanding the Gender roles.
\end{abstract}

Keywords_-Gender, Performativity, Embodiment, Masculine, Feminine, Code, Decoding.

\section{DEFINING GENDER: AN INTRODUCTION}

The term gender is used to designate psychological, social and cultural aspects of maleness and femaleness. "Gender thus is an analytical category that refers to the social organization of the relation between the sexes." and this is where Simone de Beauvoir also comes in "although even biological sex as a natural kind is now questioned by many theorists." 1949, Simone de Beauvoir is not making an argument for biological sex being natural. In fact, she is suggesting that the very fact of naming biological sex itself as male and female is tremendously arbitrary and already sort through with patriarchal power.

Generally speaking, gender, is immediate relevance to our social situations. Gender, it is a real loaded term as we sometimes enjoy gender, we sometimes suffer gender but in either case we negotiate with gender. So gender is something we negotiate with through our body, through our language, through our dress, through our embodiment.

\section{BUTLER'S: GENDER AND AFFECT}

Gender is the process of production, the process of reproduction, the process of construction, the process of deconstruction and reconstruction. Butler talks extensively in gender trouble, the idea of performativity. What is performativity? Performativity according to Butler is a kind of performance which is used to produce an affect. (AFFECT)

That affect can be an effect of wonder, basically watch a performative act and the spectacular quality of the act. Gender according to Butler depends a lot on performativity especially as gender plays out in the public space, what is masculine in a public space, what is feminine in a public space? Largely, depends on the politics of performativity, so performativity is performance which is political performance which is used and designed to generate an affect (AFFECT). Not only is it effective it is also equally affective it affects you emotionally, sentimentally it produces the structural sentiments.

Essentially that the idea of masculinity, the idea of femininity is basically a construction and replication of certain codes or behaviour. It just could be codes of conduct, codes of dressing, codes of language, codes of embodiment etc. So it is binary, it is something which we observe, internalize, as codes. So the word code is imperative in any study of gender. So it is a very defined coded system about the binary between men and women, male and female, masculine and feminine etc. In other 
words gender is a set of course which we consume, it is something which we internalize. The point is, exactly what we internalize without questioning every single day to unpack these codes to decode these divisions to recognize the binaries the constructed quality of these cultural codes. How we will keep decoding the gender division, the gender identities or the gender performances in literature as well as in real life.

Gender in other words is an asymmetrical entanglement that in biology and ideology depends to a large extent on your biological location but equally it depends to a large extent on your cultural location, on your linguistic location, on your racial location, on your political location, so all these are combined together to produce reproduce construct reconstruct gender identities. So definitions of gender, definitions of masculinity, femininity these keep changing depending on the spatial location. Now of course space and gender identity is a very complex simulator and so is language and gender identity. Language is notoriously gendered and we do not realize it all the time.

So the implication is if you are masculinising yourself you are moving upward. An act of elevation, elevated embodiment something that you do to make it better as a person, as a character. Gender as something that is a process that produces identities. These modes of production are culturally and materially mediated, so in other words, how is a male supposed to look in a particular culture, how is the female supposed to look in a particular culture. Now these are not abstract phenomenon's, these are very nasty phenomenon and depends on the cultural commodities, it depends on the economy, so all these things are enmeshed in any study of gender.

The moment of division happened when the moment of binary took place the automatic next step was to gender it. When we talk about the rational self, a logical mind, a thinking mind is male, it was immediately masculinized whereas the emotional body is female but this is the beginning, this is one in many ways where gender divisions were introduced in knowledge, discourse, popular culture, capital etc.

The problem begins when we begin to question the value system. Why is it that there are certain kinds of expectations for men and women in the same culture and from culture to culture. Why is it that they are notoriously cultural sensitive, the reason is value systems are abstract, neglecting the real historical, social, scientific situations, which consumes these gender binaries premises.

A very famous quotation by the French feminist same and Duvall who mentioned "I think that one is not born one becomes the woman." The process of becoming a woman is a complex process it moves from language to political situation to racial situation so it is a constant process and this is in connection to with what Butler said much later essentially where she said "Gender is a verb, gender is a process of happening with the process of construction, deconstruction, reconstruction." In other words, Duvall meant that one is not born one becomes the woman, there is certain code which has been produced culturally, politically, materially, economically and the whole agenda of becoming a woman is to conform to the code through your life, through your language, through your value system, say if you conform to that code you essentially become the woman. The moment you conform to the code you become neatly a woman but certainly, these codes change from time to time.

This kind of gender division was promoted and was celebrated glorified in a massive kind of way. So the relationship between value and gender is quite complex, the relationship between language and gender is quite complex because any study of feminism would reveal to us the language of matter is really deeply patriarchal, it is something which is embedded in patriarchy. Its full of these codes of patriarchy. Patriarchy has produced and perpetuated knowledge.

Pride and Prejudice, is a deeply gender text where the men control the capital, the property and the woman are just made to look pretty, make themselves attractive before men. Mother be anxious to get her daughters married. According to society, marriage becomes the most important and most convenient way for a woman to have a good life. Entire idea of being a woman is to appear attractive in the marriage market and then your life is settled. Certainly, not a happy scenario at all but this is what happens in Pride and Prejudice to a great extent.

\section{MASCULINITY AND FEMININITY}

Gender has a lot to do with agency masculinity, femininity what you are as a biological man, as a biological woman has got lot to do with agency. How gender becomes the prison-house? How you can be imprisoned by your insufficient gender identity? Answering it, because of your racial location and because of your biological location. How gender or gender identities or the production of gender identities is deeply complex in the sense that it sometimes liberates. Gender is something that we do, it is not something that we are sort of born with, every one of us is born with a biological body, but gender is something which you do with the body. Gender is something which you performed right through our language, our dress, our rituals, our religions, our political privileges, our racial locations etc it is a 
deeply material process, it is deeply ideological process. It is a performative process, it performs, it constructs certain categories of power equally, it constructs different categories of powerlessness in other words gender is an act of construction.

The textuality of gender lies precisely in the fact that it is something which can be constructed which has been constructed and which can be deconstructed and reconstructed. Literature, offers the platform which would be the buffer between the real configurations of gender, the unreal configurations of gender and the theoretical configurations of gender.

Performativity is a deliberately designed performance and because it is deliberately designed it is often excessive, actually it is often dramatic, it is spectacular and is often larger-than- life. It produces emotions such as awe, reverence, fear, respect, love and sometimes a combination of all these emotions. In what way is performativity an important component of gender studies. Gendered identity is what we perform and the way we perform a certain kind of gender in a particular manner. The performativity is an effective performance which is designed to generate a certain kind of gender identity, it could be a hegemonic gender identity, it can be a subversive gender identity, it could be a combination of a hegemonic and subversive.

Embodiment may be defined as a corporeal, psychological, material and abstract apparatus with which one navigate across and interact with the immediate environment. The embodiment is the material phenomenon as well as the abstract phenomenon. It is something which really happens to the body, to the mind, to the nerves, to the neural mechanism, the motor mechanism which humans use as thinking, feeling and it is an extended cultural phenomenon as well. What does this apparatus do and what it help us to do? It helps to navigate, it gives a sense of self, it gives a sense of the body, ownership on self with which one navigate across and interact with the immediate environment.

The hegemonic gender, dominant gender, subversive gender, and marginalize gender are all different kinds of gender which are created through performativity and embodiment. Performativity and embodiment both are process of constructing a certain sense of self.

\section{CONCLUSION}

The notion of gender depends on the body of the person, the sexuality of the person but equally depends on the acceptance of the body, the acceptance of the sexuality of the person and in a certain cultural context it is quite ideological and discursive.

The relationship between embodiment and performativity specially in relation to gender identity. Gender as something which can sometimes potentially transcend or transgress biological identity. Gender identity can sometimes be different from biological identity. Biologically you could be a man or a woman but you know your gendered self. Your gender identity could be different and the way in which this difference is produced is through performativity and through different orders of embodiment.

Thus, Gender is the process of becoming as well as a process of unbecoming. Gender is not a static concept, gender is a dynamic process, a dynamic process which is informed by the biological identity. But it can also potentially override the biological identity, it can transgress the biological identity, it can produce a different identity, the identity which you know is designed by difference.

\section{REFERENCES}

[1] Butler, J. (2021). Gender Trouble: Feminism and the Subversion of Identity 2nd edition by Butler, Judith (1999) Paperback. Routledge.

[2] de Beauvoir, S. (2015). By Simone de Beauvoir - The Second Sex (Vintage Feminism Short Edition) (2015-0320) [Paperback]. Vintage Classics.

[3] Evans, M., Hemmings, C., Henry, M., Johnstone, H., Madhok, S., Plomien, A., \& Wearing, S. (2014). The SAGE Handbook of Feminist Theory (1st ed.). SAGE Publications Ltd.

[4] Rivkin, J., \& Ryan, M. (2021). Literary Theory: An Anthology, 2nd Edition (2nd ed.). Blackwell.

[5] What's the Problem With Feminism? (n.d.). MM.NET. https://markmanson.net/whats-the-problem-with-feminism 